\title{
Lifelong Nutritional Omega-3 Deficiency Evokes Depressive-Like State Through Soluble Beta Amyloid
}

\author{
Maria Grazia Morgese $^{1}$ - Paolo Tucci ${ }^{1}$ Emanuela Mhillaj $^{2} \cdot$ Maria Bove $^{2}$. \\ Stefania Schiavone $^{1}$ - Luigia Trabace ${ }^{1}$ - Vincenzo Cuomo ${ }^{2}$
}

Received: 9 December 2015 / Accepted: 18 February 2016 / Published online: 29 February 2016

(C) Springer Science+Business Media New York 2016

\begin{abstract}
Recent evidence pointed out that the prevalence of depression has reached epidemic proportions in last decades. This increase has been linked to many environmental factors, among these the influence of dietary factors has gained great attention. In particular, it has been reported that low n-3 polyunsaturated fatty acid (n-3 PUFA) intake in diet is correlated to the development of depressive and anxiety-like symptoms. Furthermore, maternal malnutrition is a widely accepted risk factor for developing mental illness in later adulthood; among others, depression has been strongly associated to this event. On the other hand, we have previously found that acute intracerebral injection of the soluble beta amyloid 1-42 (A $\left.\beta_{1-42}\right)$ peptide induces a depressive-like behavior in rats, associated to altered hypothalamic-pituitary-adrenal (HPA) axis activation and reduced cortical serotonin and neurotrophin levels. The aim of the present work was to study the effect of pre- and post-natal ( 5 weeks post-weaning) exposure to diets differently enriched in n-3, n- 6 , as well as n-6/n-3 PUFA balanced, on immobility time displayed on the forced swimming test (FST), along with neuroendocrine quantification in offspring rats. Results showed that n-6 PUFA-enriched diet increased depressive- and anxiety-like behaviors, as shown by the elevation in the immobility time in the FST test and self-
\end{abstract}

Maria Grazia Morgese, Paolo Tucci, Luigia Trabace and Vincenzo Cuomo contributed equally to this work.

Maria Grazia Morgese

mariagrazia.morgese@unifg.it

1 Department of Clinical and Experimental Medicine, University of Foggia, Foggia, Italy

2 Physiology and Pharmacology, La Sapienza, University of Rome, Rome, Italy grooming in the open field test. Those effects were accompanied by reduced cortical serotonin, high plasmatic corticosterone and hypothalamic corticotropin-releasing factor levels. Finally, enhanced plasmatic $A \beta_{1-42}$ levels after n-6 PUFA diet and reduced plasmatic $A \beta_{1-42}$ levels after n-3 PUFA were found. Taken together, our data indicate that $A \beta_{1-42}$ might be crucially involved in behavioral alterations found after $n-$ 6 rich PUFA diet and strongly endorse the protective role of n3 and the detrimental effect of improper n-6 PUFA diet consumption.

Keywords Polyunsaturated fatty acid · Soluble beta amyloid · Depression $\cdot$ Anxiety $\cdot$ HPA axis $\cdot$ Monoamines

\section{Introduction}

Modern western diets are characterized by deficiency in content of polyunsaturated fatty acids (PUFA), in particular low consumption of fish in favor of baked and junk food has led to altered n-6/n-3 PUFA ratio. Interestingly, it has been estimated that from the dawn of the industrial revolution, the ratio $n-6 / n-$ 3 has dramatically increased. Indeed, such value moved from 1 , typical of early twentieth century, up to 15 in industrialized countries [1-3]. While n-3 PUFA are precursors of neuroprotectins and resolvins holding anti-inflammatory properties, $n-6$ PUFA are precursors, among others, of prostaglandins é, pro-inflammatory molecules responsible for modulating the activity of inflammatory cytokines. Biologically important PUFA, such as docosahexaenoic acid (DHA, 22:6n-3) and arachidonic acid (AA, 20:4n-6), can be supplied either directly from diet or by metabolic conversion of their essential precursors $\alpha$-linolenic acid (18:3n-3) and linoleic acid (18:2n-6), respectively. While in mammals, the synthesis of such precursors cannot be performed de novo, the 
enzymatic conversion relies on the action of two desaturases, $\Delta 5$ and $\Delta 6$ present on the endoplasmic reticulum, and retroconversion of DHA takes then place in peroxisomes. Although in mammals such enzymatic elongation is possibly occurring, some evidence has underlined that in humans this conversion may result inefficient, thus tissue concentrations of these lipids are closely related to diet intake [4]. The n-6 derivative, AA, plays a crucial physiological role being an important precursor of bioactive mediators. This molecule has been shown to activate protein kinases and ion channels leading to enhanced synaptic transmission [5]. Moreover, AAderived mediators have been shown to act as retrograde messengers in hippocampal long-term potentiation $[6,7]$ and to be involved in cortical neuron migration [8].

N-3 PUFA have been reported to regulate membrane fluidity and to exert their central action by modulating synaptogenesis and neurotrophic factor expression [9]. Indeed, these lipids are essential to assure proper brain functioning considering that DHA content is higher in cerebral rather than any other tissue [10].

On the other hand, the high ratio $n-6 / n-3$ is particularly unfavorable for proper central nervous system (CNS) functioning. Indeed, when diets are particularly poor in n-3 PUFA, endoreticulum, as well as peroxisomes, metabolically produce $n-6$ derivatives, namely $n-6$ docosapentaenoic acid (22:5n-6), whose insertion into biological membranes, in place of DHA, is considered the main process responsible of CNS dysfunction [11].

It is worth to note that, during embryonic life and lactation, PUFA intake exclusively depends on maternal diet, as the metabolic conversion of essential precursors cannot be accomplished [12]. Interestingly, evidence from human studies indicates that maternal metabolic state and malnutrition influence dramatically the risk for developing psychiatric complications in later adulthood [13]. Unfortunately, it is quite reasonable to assume that this nutritional-poor diet will be later perpetuated, considering that it represents part of a lifestyle acquired during early childhood. Accordingly, epidemiological evidences have established a negative correlation between n-3 PUFA consumption and development of anxiety, depression, as well as physiological distress [14-16]. These findings were supported by clinical studies indicating that low content of n-3 PUFA in diet is linked to an increased susceptibility to psychiatric disorders like depression $[17,18]$. In addition, $\mathrm{n}-3$ supplementation alone or in adjunctive therapies showed positive results in the treatment of this mental disorder [19]. Such beneficial effects were also endorsed in a recent updated meta-analysis of randomized controlled trials investigating the efficacy of n-3 PUFA treatment in depressive disorders [20], as indicated by recent guidelines from British Association for Psychopharmacology [21].

Recently, great importance has been given to soluble beta amyloid $_{1-42}\left(A \beta_{1-42}\right)$ peptide in the development of depression $[22,23]$. Indeed, it is known that some forms of depression, particularly in elderly, may represent prodromal manifestations of Alzheimer's Disease (AD), or alternatively a subtype of a mood disorder associated to amyloid burden, featured by cognitive impairment and risk of dementia [24].

In this context, chronic stress is another environmental risk factor for the development of depressive symptoms. In this regard, dysregulation of hypothalamic-pituitary-adrenal (HPA) axis in response to chronic or repeated stressful events has been reported as a crucial mechanism [25]. Low cerebral DHA content, secondary to poor diet, has been associated to increased anxiety-like behavior induced by chronic mild stress paradigm in animals [26]. Accordingly, it has been reported that a diet enriched in n- 6 fatty acids increased aggressive behavior in rodents, while high n-3 PUFA diet was able to reduce the stress response $[27,28]$, indicating that also $n-6$ PUFA content plays a central role.

Therefore, in the present study we evaluated the effects of pre- and post-natal exposure to diet enriched in either n-3 or n6 PUFA, as well as to $n-6 / n-3$ balanced diet, as controls, in male rat offspring. In particular, we evaluated the development of depressive and anxiety-like behaviors in rats, corroborating behavioral outcomes with measures of plasmatic $A \beta$ levels, HPA axis parameters, and monoamine concentrations in prefrontal cortex (PFC), a brain region crucial in depression and where DHA plays a major role in neural maturation [29].

\section{Materials and Methods}

\section{Animals}

Adult (250-300 g) Wistar rats (Harlan, S. Pietro al Natisone, Udine) were used in this study. They were housed at constant room temperature $\left(22 \pm 1{ }^{\circ} \mathrm{C}\right)$ and relative humidity $(55 \pm 5 \%)$ under a 12-h light/dark cycle with ad libitum access to food and water. Procedures involving animals and their care were conducted in conformity with the institutional guidelines of the Italian Ministry of Health (D.L. 26/2014), the Guide for the Care and Use of Mammals in Neuroscience and Behavioral Research (National Research Council 2004), the Directive 2010/63/EU of the European Parliament and of the Council of 22 September 2010 on the protection of animals used for scientific purposes. All procedures involving animals were conducted in accordance to ARRIVE guidelines. Animal welfare was daily monitored through the entire period of experimental procedures. No signs of distress were evidenced, anyway all efforts were made to minimize the number of animals used and their suffering.

\section{Diets}

One male and two female rats were housed together for mating. Animals were exposed to specific diets mimicking 
lifelong n-6/n-3 imbalance of PUFA as previously described $[12,30]$. In particular, after mating dams were randomly assigned to the group fed with either a diet containing $6 \%$ total fat in the form of only rapeseed oil (n-3 enriched, rich in linolenic acid 18:3n-3) or peanut oil (n-6 enriched, rich in linoleic acid 18:2n-6) throughout gestation and lactation. As control group, dams were fed with a diet containing $6 \%$ total fat in the form of $3 \%$ of peanut oil plus $3 \%$ of rapeseed oil, called n-6/n-3 diet. After weaning, offsprings continued to be subjected to the same diet throughout life. All experiments were then performed in male 8-week-old rats.

\section{Open Field Spontaneous Locomotor Activity}

The open field (OF) apparatus consisted of a circular arena, $75 \mathrm{~cm}$ diameter, made of dark plastic under dim lighting, as previously described by Monteggia et al. [31]. The experimental sessions were videotaped by a camera fixed above the arena. Animals were acclimatized to the test room for $1 \mathrm{~h}$ before each test. Motor activity was measured by placing the rat into the center of the arena before a 20 -min session. The scoring was performed using a video-tracking motion analysis system (ANY-MAZE, San Diego Instrument, San Diego, CA). To assess general locomotor activity, the following behavioral parameters (expressed as frequency on 5 min counts) were scored: number of square limit crossings with both forepaws, rearing (standing with the body inclined vertically, forequarters raised), and wall rearing (standing on the hind limbs and touching the walls of the apparatus with the forelimbs). To investigate anxiety-related behavior, we measured time spent performing general grooming activity consisting of the following: face grooming (strokes along the snout), head washing (semicircular movements over the top of the head and behind the ears), and body grooming (body fur licking) [32]. Time spent in center and periphery was quantified as measure of anxiety-like behavior.

\section{Forced Swimming Test}

The forced swimming test (FST) is a reliable task for discriminating depressive state in animals and is widely used for predicting antidepressant properties of drugs [33]. On the first of the two test days, animals were placed individually in inescapable Perspex cylinders (diameter $23 \mathrm{~cm}$; height $70 \mathrm{~cm}$ ) filled with water at constant temperature of $25 \pm 1{ }^{\circ} \mathrm{C}$ at $30 \mathrm{~cm}$ of height [34].

During the preconditioning period, animals were videotaped for $15 \mathrm{~min}$. Then, rats were removed and dried before being returned to their home cages. Twenty-four hours later, each rat was positioned in the water-filled cylinder for $5 \mathrm{~min}$. This session was video-recorded and subsequently scored by an observer blind to the treatment groups. During the test sessions, the frequency that the rats spent performing the following behaviors was measured: struggling (time spent in tentative of escaping), swimming (time spent moving around the cylinder), and immobility (time spent remaining afloat making only the necessary movements to keep its head above the water). Data were expressed as frequency on $5 \mathrm{~s}$ counts.

\section{Post-Mortem Tissue Analysis}

Rats were euthanized and brains were immediately removed and cooled on ice for dissection of target regions (PFC, hypothalamus) according to the atlas of Paxinos and Watson (1998). Tissues were frozen and stored at $-80^{\circ} \mathrm{C}$ until analysis was performed.

\section{Monoamine Quantifications}

Serotonin (5-HT) and noradrenaline (NA) concentrations were determined by high performance liquid chromatography (HPLC) coupled with an electrochemical detector (Ultimate ECD, Dionex Scientific, Milan, Italy). Separation was performed by a LC18 reverse phase column (Kinetex, $150 \times 4.2 \mathrm{~mm}$, ODS $5 \mu \mathrm{m}$; Phenomenex, Castel MaggioreBologna, Italy). The detection was accomplished by a thinlayer amperometric cell (Dionex, ThermoScientifics, Milan, Italy) with a 5-mm diameter glassy carbon electrode at a working potential of $0.400 \mathrm{~V}$ vs. Pd. The mobile phase used was $75 \mathrm{mM} \mathrm{NaH}_{2} \mathrm{PO}_{4}, 1.7 \mathrm{mM}$ octane sulfonic acid, $0.3 \mathrm{mM}$ EDTA, acetonitrile $10 \%$, in distilled water, buffered at $\mathrm{pH}$ 3.0. The flow rate was maintained by an isocratic pump (Shimadzu LC-10 AD, Kyoto, Japan) at $1 \mathrm{ml} / \mathrm{min}$. Data were acquired and integrated using Chromeleon software (version 6.80, Dionex, San Donato Milanese, Italy).

\section{ELISA Quantifications}

Plasma samples were analyzed for corticosterone and $\mathrm{A} \beta$ by using ELISA kits provided by Tebu-bio (Magenta, Milan, Italy) and Cloud-Clone Corporation (Houston, Texas, USA), respectively. Corticotropin-releasing factor (CRF) quantification was performed in hypothalamic area by using ELISA kits provided by Tebu-bio (Magenta, Milan, Italy). Assays were performed according to the manufacturer's instructions. Each sample analysis was carried out in duplicate to avoid intraassay variations.

\section{Statistical Analysis}

Results were expressed as mean \pm S.E.M. Statistical analyses were performed using Graph Pad 5.0 (GraphPad Software, San Diego, CA) for Windows. Behavioral and neurochemical data were tested for normality and then analyzed by using two-way analysis of variance (ANOVA) for repeated 
measures or one-way ANOVA followed by Bonferroni's or Tukey's multiple comparisons test, as required. Differences were considered statistically significant when $P$ value was less than 0.05 .

\section{Results}

\section{Effects of N-3 and N-6 PUFA-Enriched Diets on Body Weight Gain}

Offspring rats fed with n-3, n-6 PUFA, and n-6/n-3 (control) diets were weekly weighted in order to monitor general health status. Analysis of data evidenced no differences in total body weight gain among groups $(210.2 \pm 5.0 \mathrm{~g}, 200.0 \pm 3.3 \mathrm{~g}, 195.8$ $\pm 5.0 \mathrm{~g}$, for animals fed with n-6/n-3, n-3, and n-6 PUFA diet, respectively; one-way ANOVA followed by Tukey's multiple comparison test, n.s.). Moreover, we estimated the total food intake and no statistically significant differences were individuated $(439.9 \pm 74.2 \mathrm{~g}, 385.4 \pm 61.8 \mathrm{~g}, 296.9 \pm 74.8 \mathrm{~g}$, for animals fed with n-6/n-3, n-3, and n-6 PUFA diets, respectively; one-way ANOVA followed by Tukey's multiple comparison test, n.s.)

\section{Effects of N-3 and N-6 PUFA-Enriched Diets on FST}

In order to determine if pre- and post-natal exposure to either n-3 or n-6 PUFA-enriched diet was able to influence emotional behavior, we performed the FST on experimental groups. N-6 PUFA-enriched diet significantly increased the immobility frequency compared to control and n-3 PUFA rich diet (Fig. 1a, one-way ANOVA followed by Bonferroni's multiple comparison test, $P<0.01$ n-3 versus n-6 PUFA, and $P<0.001$ n-6 PUFA versus n-6/n-3 balanced diet). Moreover, swimming and struggling frequencies were significantly decreased in n-6 PUFA diet-exposed animals (Fig. 1b, c, one-way ANOVA followed by Bonferroni's multiple comparison test, swimming $P<0.01$ n-3 versus n-6 PUFA, and $P<0.001$ n-6
PUFA versus n-6/n-3 balanced diet; struggling $P<0.01$ n-6 PUFA versus n-6/n-3 balanced diet).

\section{Effects of N-3 and N-6 PUFA-Enriched Diets on OF}

In order to verify whether the effects observed in the FST could not be related to an alteration in locomotion, we accomplished the OF test. These experiments were carried out in another set of rats to avoid inter-assay interference. Statistical analyses revealed a significant effect only on time in crossing and wall rearing frequencies (Fig. 2a, c, two-way ANOVA for repeated measures, crossing $P<0.001 \mathrm{~F}_{3,21}=53.62$; wall rearing $P<0.001 \mathrm{~F}_{3,21}=38.19$ ). Moreover, no impairment associated to diet exposure was evidenced in either vertical or horizontal activity, as revealed by crossing, rearing, and wall rearing frequency measurements (Fig. 2a-c, two-way ANOVA for repeated measures followed by Bonferroni's multiple comparison test, n.s.). In the same test, self-grooming behavior was quantified as index of anxiety-like state. We found that n-6 PUFA diet significantly increased the time that rats spent performing selfgrooming (Fig. 3a, one-way ANOVA followed by Bonferroni's multiple comparison test, $P<0.05$ n- 6 versus n-3 PUFA and n6/n-3 balanced diet). No differences were observed in the time spent in periphery or center area of the arena (Fig. 3b, c, oneway ANOVA followed by Bonferroni's multiple comparison test, n.s.).

\section{Effects of N-3 and N-6 PUFA-Enriched Diets on 5-HT and NA Levels in PFC}

In order to corroborate behavioral with neurochemical data, we quantified 5-HT and NA content in PFC of PUFA-enriched diet fed animals. We found that cortical 5-HT concentrations were significantly lower in animals pre- and post-natal fed with n-6 PUFA-enriched diet compared to controls (Fig. 4a, one-way ANOVA followed by Bonferroni's multiple comparison test, $P<0.05)$. On the other hand, NA was significantly increased in n-3 PUFA-treated rats compared to either n-6
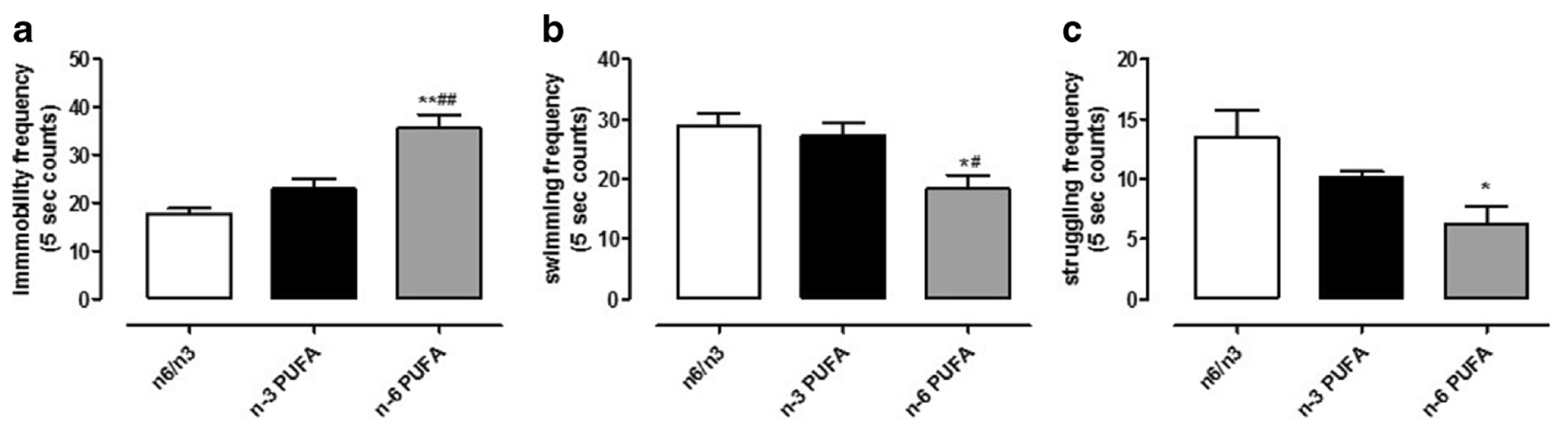

Fig. 1 Effects of n-3, n-6, and n-6/n-3 balanced PUFA diet on FST. Frequency measure of immobility (a), swimming (b), and struggling (c) behaviors in rats fed from conception until 5 weeks post-weaning with n6/n-3 balanced diet (white bar), n-3 PUFA diet (dark bar), and n-6 PUFA diet (gray bar). Data are expressed as mean \pm SEM. One-way ANOVA followed by Bonferroni's multiple comparison test $* P<0.05$, $* * P<0.01$ versus n-3 PUFA and ${ }^{\#} P<0.05,{ }^{\# \#} P<0.01$ versus n- $6 / \mathrm{n}-3$ balanced diet 

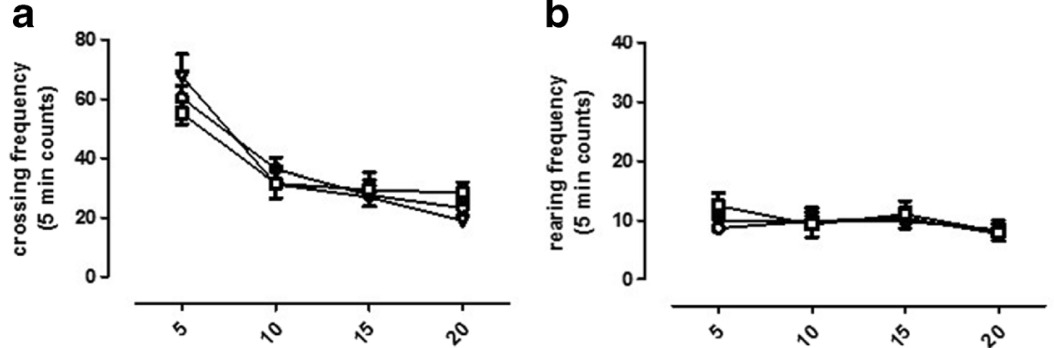

C

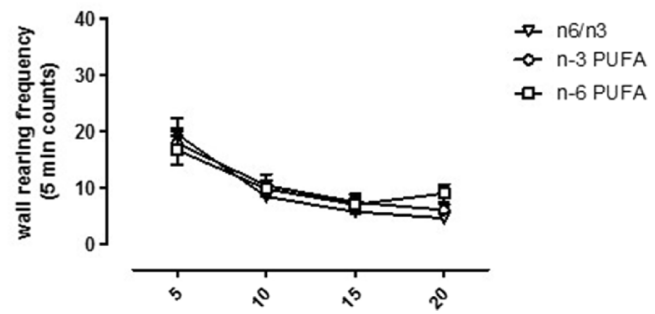

Fig. 2 Effects of n-3, n-6, and n-6/n-3 balanced PUFA diet on locomotive index in OF. Frequency measure of crossing (a), rearing (b), and wall rearing (c) in rats fed from conception until 5 weeks postweaning with n-6/n-3 balanced diet (empty triangle), n-3 PUFA diet

PUFA or controls animals (Fig. 4b, one-way ANOVA followed by Bonferroni's multiple comparison test, $P<0.05)$.

\section{Effects of N-3 and N-6 PUFA-Enriched Diets on HPA Axis}

We quantified hypothalamic CRF and plasmatic corticosterone levels. We found that $\mathrm{CRF}$ content was significantly increased after n-6 PUFA in respect to control diet (Fig. 5a, oneway ANOVA followed by Bonferroni's multiple comparison test, $P<0.05$ n-6 PUFA fed rats versus balanced diet controls). Accordingly, n-6 PUFA diet was also able to enhance corticosterone levels compared to n-3 PUFA-treated and controls animals (Fig. 5b, one-way ANOVA followed by Bonferroni's multiple comparison test, $P<0.05$ ).

\section{Effects of N-3 and N-6 PUFA-Enriched Diets on Plasmatic A $\beta$ Levels}

We quantified plasmatic soluble $A \beta$ peptide in offspring of rats differently exposed to n-3, n-6 PUFA, and n-6/n-3 balanced diets. We found that, while animals exposed throughout their life to n-6 PUFA-enriched diet had a significant increase in plasmatic $A \beta$ levels compared to controls, high n-3 PUFA diet significantly decreased such levels (Fig. 6, one-way ANOVA followed by Bonferroni's multiple comparison test, (empty circle), and n-6 PUFA diet (empty square). Two-way ANOVA for repeated measures followed by Bonferroni's multiple comparison test Data are expressed as mean \pm SEM

$P<0.001$ n-6 PUFA versus n-6/n-3 and $P<0.05$ n-3 and n-6 PUFA versus n-6/n-3, respectively).

\section{Discussion}

In the present study, we evaluated the effects of pre- and postnatal rat exposure to n-3 and n-6 PUFA-enriched diets on behavioral outcomes resembling human depressive- and anxiety-like symptoms. Our findings clearly indicated that exposure during entire life to a diet enriched in n-6 PUFA induced a depressive- and anxiety-like state in adult offspring. In these animals, behavioral outcomes were accompanied by hyperactivation of HPA axis, alteration of cortical monoamine content and increased plasmatic $\mathrm{A} \beta_{1-42}$ levels.

In our model, rats were fed with PUFA-enriched diets from conception until experimental day. This paradigm simulates human conditions where children are fed with poor n-3 PUFA diet during gestation, nursing, up to young adulthood. Here, we found that n-6 PUFA-enriched diet that should correspond to a depauperation of central n-3 fatty acids [35] increased immobility frequency in the FST. This behavioral test relies on the learned helplessness paradigm that ultimately results in symptoms resembling depression. This behavioral paradigm is widely considered reliable for discriminating depressive-
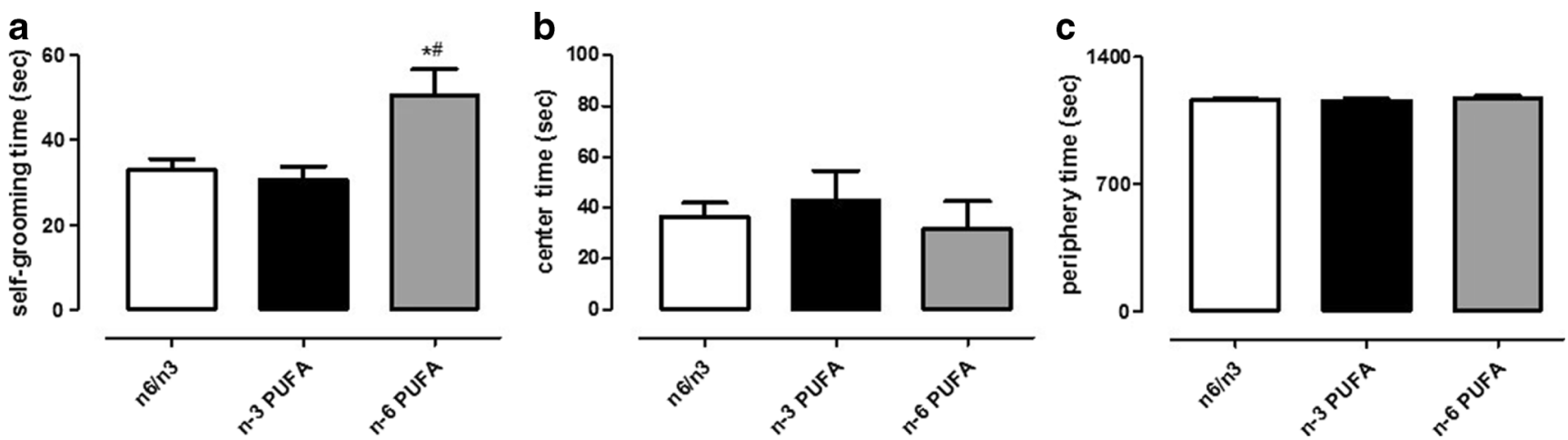

Fig. 3 Effects of n-3, n-6, and n-6/n-3 balanced PUFA diet on anxietylike index in OF. Measure of time spent performing grooming (a), time in center (b), and in periphery (c) in rats fed from conception until 5 weeks post-weaning with n-6/n-3 balanced diet (white bar), n-3 PUFA diet (dark bar), and n-6 PUFA diet (gray bar). Data are expressed as mean \pm SEM. One-way ANOVA followed by Bonferroni's multiple comparison test $* P<0.05$ versus $\mathrm{n}-3$ PUFA and $\# P<0.05$ versus $\mathrm{n}-6 / \mathrm{n}-3$ balanced diet 


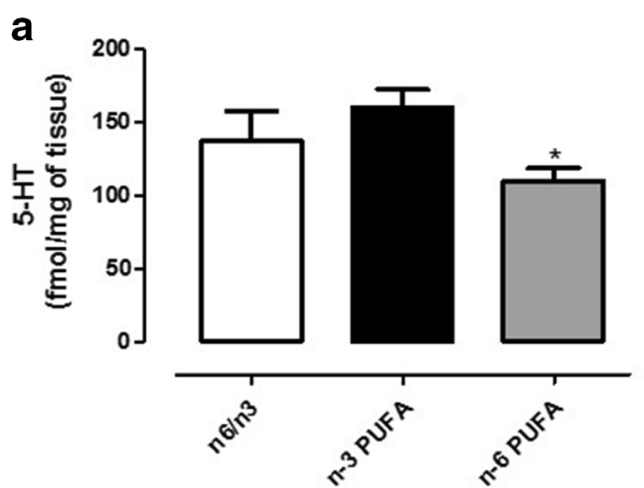

Fig. 4 Effects of n-3, n-6, and n-3/n-6 balanced PUFA diet on cortical monoamine levels. Measure of 5-HT (a) and NA content (b) in PFC of rats fed from conception until 5 weeks post-weaning with n-6/n-3 balanced diet (white bar), n-3 PUFA diet (dark bar), and n-6 PUFA diet

like state, as well as predicting antidepressant properties of drugs [33]. We can rule out the possibility that such increased immobility could have been due to alteration in locomotion, since no impairment in vertical and horizontal activities was found in the $\mathrm{OF}$ test. On the other hand, the $\mathrm{OF}$ revealed that n-6 PUFA fed rats spent more time in performing selfgrooming, an index of anxiety-like behavior in rodents [36].

Our findings are in line with previous studies, in humans and animals, linking poor n-3 PUFA diet with depression and anxiety [29, 37-39]. Many mechanisms have been proposed in order to explain such effects. Essential fatty acids play a central role in CNS, taking into account that long chain fatty acids, as DHA, are integrant part of neuronal membrane. They control membrane fluidity, as well as neuronal plasticity. Imbalance in maternal micronutrients has been found to reduce cortical DHA, and brain-derived neurothrophic factor (BDNF), while n-3 PUFA supplementation was shown to protect such neurotrophin. Furthermore, deficiency in n-3 PUFA intake, especially in perinatal period, is linked to decreased BDNF [35] and low BDNF levels have been described after

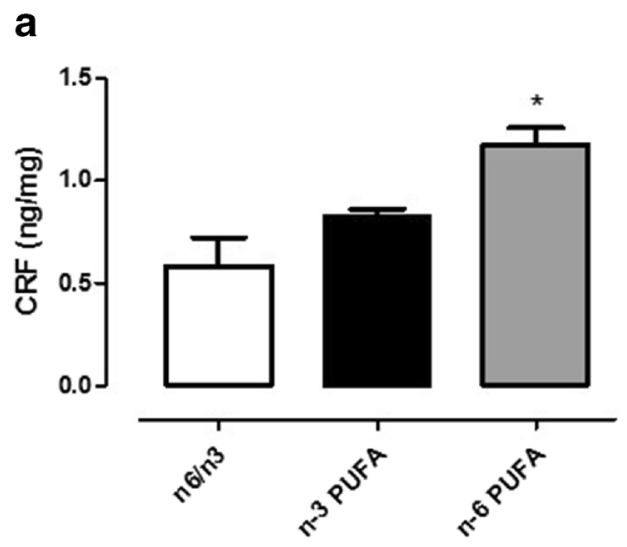

Fig. 5 Effects of n-3, n-6, and n-6/n-3 balanced PUFA diet on hypothalamic CRF and plasmatic corticosterone quantification. Measure of hypothalamic CRF content (a) and plasmatic corticosterone levels (b) in rats fed from conception until 5 weeks post-weaning with n-

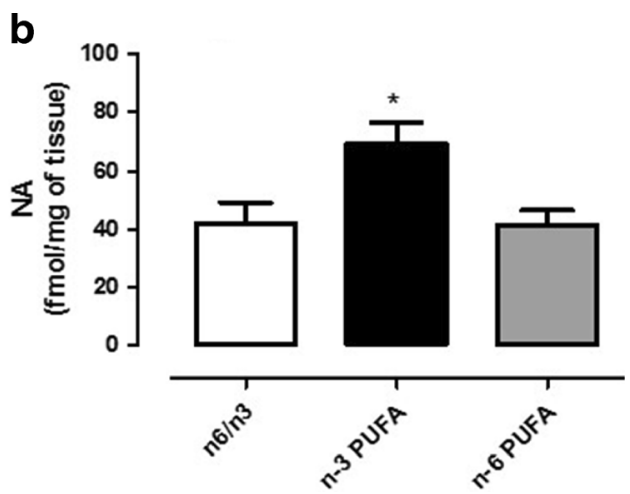

(gray bar). One-way ANOVA followed by Tukey's multiple comparison test data are expressed as mean \pm SEM. $* P<0.05$ versus $n-3$ PUFA and $\# P<0.05$ versus $\mathrm{n}-6 / \mathrm{n}-3$ balanced diet

prenatal stress [40]. Glucocorticoids have been related to such an effect, since corticosterone is able to down-regulate both mRNA and protein BDNF [41, 42]. In this light, mice overexpressing glucocorticoids showed an increased anxiety-like behavior [43] and Larrieu and Colleagues have demonstrated that n-3 PUFA deficiency can influence neuronal cortical morphology and depressive-like behavior through corticosterone secretion [39]. Furthermore, they showed that a condition of poor n-3 diet intake induces a phenotype comparable to one induced by chronic social defeat stress and high corticosterone levels were also described [39]. Accordingly, in our model we found increased hypothalamic CRF release as well as increased plasmatic corticosterone levels in n-6 PUFA fed animals, further demonstrating a hyperactivity of HPA axis. High cortisol levels, and thus HPA-axis hyperactivity, have been indicated as the most frequent alteration in patients affected by major depression disorder [44]. Supplementation of $n-3$ PUFA may thus result beneficial given the described prophylactic role in depression [45]. On the other hand, another neurotrophic factor that has been implicated in the neurobiology

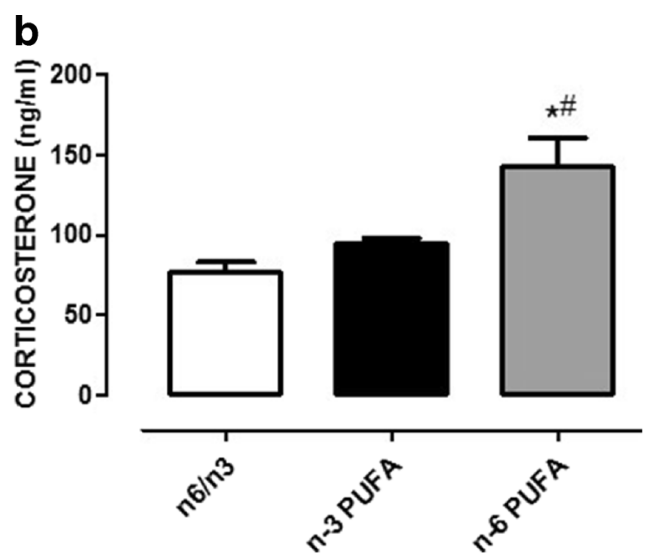

6/n-3 balanced diet (white bar), n-3 PUFA diet (dark bar), and n-6 PUFA diet (gray bar). Data are expressed as mean \pm SEM. One-way ANOVA followed by Tukey's multiple comparison test $* P<0.05$ versus n-3 PUFA and $\# P<0.05$ versus $n-6 / n-3$ balanced diet 


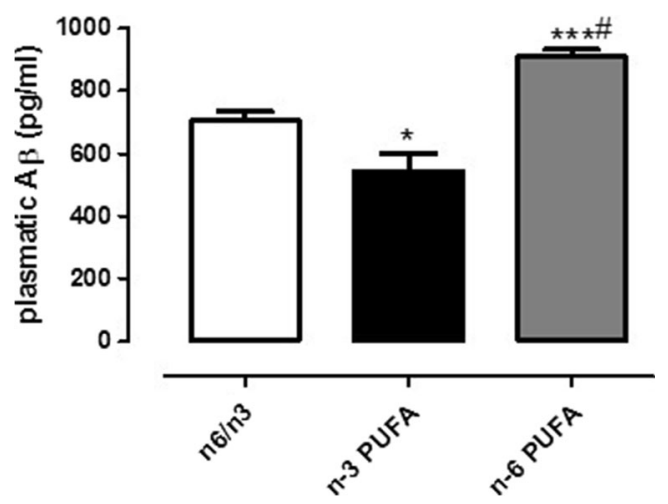

Fig. 6 Effects of n-3, n-6, and n-6/n-3 balanced PUFA diet on plasmatic $A \beta_{1-42}$ quantification. Measure of plasmatic $A \beta_{1-42}$ in rats fed from conception until 5 weeks post-weaning with $n-6 / n-3$ balanced diet (white bar), n-3 PUFA diet (dark bar), and n-6 PUFA diet (gray bar). Data are expressed as mean \pm SEM. One-way ANOVA followed by Tukey's multiple comparison test $* P<0.05$ and $* * * P<0.001$ versus $\mathrm{n}$ 3 PUFA and $\# P<0.05$ versus $\mathrm{n}-6 / \mathrm{n}-3$ balanced diet

of depression and chronic stress exposure is transforminggrowth factor- $\beta 1$ (TGF- $\beta 1$ ) [46]. TGF- $\beta 1$ has a constitutive role in inflammation suppression and protects neuron from toxic insults in the CNS acting as neurotrophic factor [46]. Furthermore, TGF- $\beta 1$ may enhance synaptic plasticity via increased BDNF and its receptor, trkB, expression [47]. In particular, reduced levels of this factor have been reported in major depressed patients and antidepressant treatments have been reported to increase TGF- $\beta 1$ levels [48]. Moreover, $n-3$ PUFA supplementation has been shown to increase TGF- $\beta 1$ levels, both in vivo and in vitro [49, 50]. Thus, future studies are warranted in order to elucidate whether, in our experimental conditions, n-3 PUFA deficiency could lead to depressive state also by altering TGF- $\beta 1$ signaling.

In addition, other mediators beyond neurotrophins could be rather implicated. Activation of endocannabinoid system, whose endogen ligands are derived from AA, seems to play a significant role in attenuating stress response and HPA axis stimulation [51, 52]. In addition, alterations in this system have been reported after poor maternal n-3 PUFA intake [12]. Endocannabinoids control mood and emotional phenotype and depressive and anxiety-like behaviors have been shown to be improved by increasing their levels [53, 54].

In keeping with this hypothesis, prefrontal cortical endocannabinoids require functional serotonergic tone in order to promote active stress coping response [55]. In our experimental conditions, we found that cortical 5-HT concentrations were significantly decreased in animals fed with n-6 PUFA diet. The PFC is the most enriched area in DHA and it has been shown that, after poor diet intake, this brain region is the most sensitive to DHA depauperation [17]. Such low levels of 5-HT support behavioral outcomes. Indeed, immobility and swimming frequency in FST are regulated by serotonergic transmission. In particular, high 5-HT levels, consequent to selective re-uptake inhibitors, are commonly associated to increased swimming and reduced immobility behavior $[34,56]$. In a recent publication, Patrick and Ames proposed a possible mechanism underlying the modulatory role of micronutrients, such as n-3 PUFA and vitamin D, on 5-HT synthesis [57]. According to Authors, EPA enhances 5-HT release pre-synaptically through reduction of central prostaglandins of E2 series, responsible of inhibiting its release. Furthermore, DHA, by increasing cell membrane fluidity, facilitates 5-HT interaction with its receptors in postsynaptic neurons [57]. Based on these data, it could be hypothesized that inflammation negatively affects central serotonergic system. In this regard, the anti-inflammatory effects of n-3 PUFA have been reported, since DHA was shown to reduce eicosanoid synthesis along with AA production $[58,59]$ and to decrease inflammatory cytokine levels [60]. Furthermore, Madore and Colleagues have elegantly shown that $n-3$ deficiency during gestation and lactation leads to altered microglia motility, as well as altered microglia phenotype [35], prompting these Authors to hypothesize that such deficiency induced a state that resembles the so-called pseudoinflammation or sterile inflammation, described in absence of pathogens [61]. Reduction in 5HT levels has also been linked to anxiety-like behavior, since genetic manipulations that lead to drastic 5-HT depauperation result in higher susceptibility to stress, while treatments that increase 5-HT result in a highly anxiolytic phenotype [62, 63]. Despite 5-HT role in anxiety is well established, NAergic role remains less defined. In particular, we found that after n-6 PUFA-enriched diet, no alterations were found in cortical NA content, although increased CRF and corticosterone levels. Thus, these data can be considered as an impairment of stress response axis. However, we found that n-3 PUFA rich diet increased NA concentration in PFC. In this regard, it has been reported that genetic enhancement of NA tone protects animals from stress-induced depressive behavior [64].

Although NAergic transmission in the context of nutritional n-3 deficiency has received little attention, in vitro studies have demonstrated that incorporation of DHA or short exposure to this molecule in SH-SY5Y cultured cells result in increased basal NA release through enhanced exocytosis [65]. In addition, we can speculate that the effect of n-3 PUFA on noradrenergic system could reflect a neuroprotective phenomenon. Indeed, NA has been shown to regulate glial activation and strategies that lead to increased NA levels have been proposed as a valid approach to cure several neurodegenerative diseases [66]. In this regard, in vitro studies have evidenced a protective effect of NA toward toxicity induced by $A \beta_{1-42}$ via activation of neurotrophic pathways $[67,68]$. Moreover, reduced NA concentrations in locus coeruleus projecting areas facilitate the inflammatory reaction of microglial cells after $A \beta_{1-42}$ exposure, thus impairing microglial migration and phagocytosis, thereby decreasing $A \beta$ clearance [69]. Interestingly, it has been reported that $n-$ 3 PUFA supply enhances microglial phagocytosis of $A \beta_{1-42}$ 
[70]. On the other hand, in our unpublished observation, central $\mathrm{A} \beta_{1-42}$ administration leads to enhanced cytokine levels, in particular we found high cortical interleukin-1 $\beta$ (IL-1 $\beta$ ) content. Accordingly, we previously described increased hippocampal IL- $1 \beta$ release following local $\mathrm{A} \beta_{1-42}$ injection [71]. Enhanced IL-1 $\beta$ levels have also been linked to late-life depression [72], as well as $A \beta_{1-42}$ [73], and central IL- $1 \beta$ is considered crucial for chronic stress-induced depression [74]. Moreover, high n-3 PUFA diet can reduce IL-1 $\beta$ production [75] and, in rats, can attenuate IL- $1 \beta$-induced stress/ anxiety response [76]. In keeping with these data, our in vivo results strongly support such hypothesis, since n-3 PUFA fed animals had decreased plasmatic $A \beta_{1-42}$ levels. Although in humans, plasmatic $A \beta_{1-42}$ is not used as markers of $A D$ diagnosis or progression yet, in rodents it has been finely demonstrated that plasmatic levels reflects cerebrospinal levels in a dose-dependent fashion [77]. In addition, increased consumption of n-3 PUFA in healthy elderly was associated to lower A $\beta_{1-42}$ plasma levels [78]. However, this was a crosssectional study connoted by the fact that nutritional information were taken with a questionnaire and not all nutrients or daily habits were considered. Conversely, in our experimental protocol, many variables were controlled. Animals were subjected to same external conditions, food and body weight were weekly monitored, indicating no differences. Moreover, our animals were fed with these modified diets throughout their life, from conception until adulthood.

Accordingly enough, we found that n-6 PUFA fed rats presented increased $A \beta_{1-42}$ levels. This result may allow several considerations since we have previously demonstrated that a single intracerebroventricular administration of soluble $\mathrm{A} \beta_{1-42}$ induces a depressive-like state in rats that is accompanied by reduced cortical 5-HT and BDNF [22]. In addition, we found an altered HPA axis response after $A \beta_{1-42}$ central administration [79]. These findings strongly argue in favor of a central role of $A \beta_{1-42}$ in the development of depressive symptoms and our data indicate that this peptide might be crucially involved in behavioral alterations found consequently to high n-6 PUFA intake. Importantly, depression has been associated with prodromal stages of $\mathrm{AD}[80]$ and significantly higher levels of CSF $A \beta_{1-42}$ in humans with major depressive disorder have been reported [81].

Ultimately, we cannot completely rule out the possibility that such alteration in plasmatic $A \beta$ levels could reflect a peripheral phenomenon considering that platelets have been indicated as a major source of amyloid peptide precursor (APP) [82] and they possess the enzymatic machinery for APP metabolite production [83]. However, the central effects found in the present manuscript endorse the hypothesis that high plasmatic $A \beta$ levels can mirror central levels. In this regard, it has been reported that $\mathrm{A} \beta \mathrm{CSF}$ reflects plasmatic levels in healthy subjects, while in AD patients such equilibrium is disrupted [84].
To the best of our knowledge, this is the first study linking together the insurgence of depressive and anxiety-like state following lifelong high n-6 PUFA and n-3 deficient diets with increased plasmatic $A \beta_{1-42}$ levels. Important consideration may be drawn. Depressive disorders are very common in western countries and depression during childhood is positively associated with BMI and overweight in later life $[85,86]$. On the other hand, a dramatic increase in $\mathrm{AD}$ has been reported in developing countries as consequence of westernization of national diets either in industrialized countries, such as Japan, or developing countries [87]. In addition, the negative role of n-6 PUFA has been reported in conditions of supplementation of n-3 PUFA. In particular, while supplementing $n$ 3 PUFA is a valid strategy for reversing learning deficit induced by their deficiency, concomitant high $\mathrm{n}-6$ consumption can limit such beneficial effect [27].

\section{Conclusions}

In conclusion, our results encourage questioning the negative impact that changes in modern lifestyle occurring through years could have in health in western countries, and strongly endorse the protective role of $n-3$ and the detrimental effect of improper n-6 PUFA consumption.

Acknowledgments This study was supported by PRIN 2012 (to V.C.) from MIUR, by PRIN 2011 (to P.T.) from MIUR and by FIR 2014-2015 (to M.G.M. and S.S.) from Apulia Region.

Compliance with Ethical Standards Procedures involving animals and their care were conducted in conformity with the institutional guidelines of the Italian Ministry of Health (D.L. 26/2014), the Guide for the Care and Use of Mammals in Neuroscience and Behavioral Research (National Research Council 2004), the Directive 2010/63/EU of the European Parliament and of the Council of 22 September 2010 on the protection of animals used for scientific purposes. All procedures involving animals were conducted in accordance to ARRIVE guidelines. Animal welfare was daily monitored through the entire period of experimental procedures. No signs of distress were evidenced, anyway all efforts were made to minimize the number of animals used and their suffering.

Conflict Interest The authors declare no competing interests.

\section{References}

1. Simopoulos AP (2011) Importance of the omega-6/omega-3 balance in health and disease: evolutionary aspects of diet. World Rev Nutr Diet 102:10-21. doi:10.1159/000327785

2. Simopoulos AP (2009) Omega-6/omega-3 essential fatty acids: biological effects. World Rev Nutr Diet 99:1-16. doi:10.1159/ 000192755

3. Simopoulos AP (2009) Evolutionary aspects of the dietary omega6:omega-3 fatty acid ratio: medical implications. World Rev Nutr Diet 100:1-21. doi:10.1159/000235706 
4. Arterburn LM, Hall EB, Oken H (2006) Distribution, interconversion, and dose response of $\mathrm{n}-3$ fatty acids in humans. Am J Clin Nutr 83(6 Suppl):1467S-1476S

5. Katsuki H, Okuda S (1995) Arachidonic acid as a neurotoxic and neurotrophic substance. Prog Neurobiol 46(6):607-636

6. Bazan NG (1998) The neuromessenger platelet-activating factor in plasticity and neurodegeneration. Prog Brain Res 118:281-291

7. Williams JH, Errington ML, Lynch MA, Bliss TV (1989) Arachidonic acid induces a long-term activity-dependent enhancement of synaptic transmission in the hippocampus. Nature 341(6244):739-742. doi:10.1038/341739a0

8. Hattori M, Adachi H, Tsujimoto M, Arai H, Inoue K (1994) MillerDieker lissencephaly gene encodes a subunit of brain plateletactivating factor acetylhydrolase [corrected]. Nature 370(6486): 216-218. doi:10.1038/370216a0

9. Heinrichs SC (2010) Dietary omega-3 fatty acid supplementation for optimizing neuronal structure and function. Mol Nutr Food Res 54(4):447-456. doi:10.1002/mnfr.200900201

10. Alessandri JM, Guesnet P, Vancassel S, Astorg P, Denis I, Langelier B, Aid S, Poumes-Ballihaut C et al (2004) Polyunsaturated fatty acids in the central nervous system: evolution of concepts and nutritional implications throughout life. Reprod Nutr Dev 44(6):509538

11. McCann JC, Ames BN (2005) Is docosahexaenoic acid, an n-3 long-chain polyunsaturated fatty acid, required for development of normal brain function? An overview of evidence from cognitive and behavioral tests in humans and animals. Am J Clin Nutr 82(2):281-295

12. Lafourcade M, Larrieu T, Mato S, Duffaud A, Sepers M, Matias I, De Smedt-Peyrusse V, Labrousse VF et al (2011) Nutritional omega-3 deficiency abolishes endocannabinoid-mediated neuronal functions. Nat Neurosci 14(3):345-350. doi:10.1038/nn.2736

13. Sullivan EL, Riper KM, Lockard R, Valleau JC (2015) Maternal high-fat diet programming of the neuroendocrine system and behavior. Horm Behav. doi:10.1016/j.yhbeh.2015.04.008

14. Lang UE, Beglinger C, Schweinfurth N, Walter M, Borgwardt S (2015) Nutritional aspects of depression. Cell Physiol Biochem 37(3):1029-1043. doi:10.1159/000430229

15. Lucas M, Kirmayer LJ, Dery S, Dewailly E (2010) Erythrocyte n-3 is inversely correlated with serious psychological distress among the Inuit: data from the Nunavik health survey. J Am Coll Nutr 29(3):211-221

16. Ross BM (2009) Omega-3 polyunsaturated fatty acids and anxiety disorders. Prostaglandins Leukot Essent Fat Acids 81(5-6):309312. doi:10.1016/j.plefa.2009.10.004

17. Levant B (2013) N-3 (omega-3) polyunsaturated Fatty acids in the pathophysiology and treatment of depression: pre-clinical evidence. CNS Neurol Disord Drug Targets 12(4):450-459

18. Park Y, Moon HJ, Kim SH (2012) N-3 polyunsaturated fatty acid consumption produces neurobiological effects associated with prevention of depression in rats after the forced swimming test. J Nutr Biochem 23(8):924-928. doi:10.1016/j.jnutbio.2011.04.018

19. Lin PY, Su KP (2007) A meta-analytic review of double-blind, placebo-controlled trials of antidepressant efficacy of omega-3 fatty acids. J Clin Psychiatry 68(7):1056-1061

20. Grosso G, Pajak A, Marventano S, Castellano S, Galvano F, Bucolo C, Drago F, Caraci F (2014) Role of omega-3 fatty acids in the treatment of depressive disorders: a comprehensive meta-analysis of randomized clinical trials. PLoS One 9(5):e96905. doi:10.1371/ journal.pone.0096905

21. Cleare A, Pariante CM, Young AH, Anderson IM, Christmas D, Cowen PJ, Dickens C, Ferrier IN et al (2015) Evidence-based guidelines for treating depressive disorders with antidepressants: a revision of the 2008 British Association for Psychopharmacology guidelines. J Psychopharmacol 29(5):459-525. doi:10.1177/ 0269881115581093
22. Colaianna M, Tucci P, Zotti M, Morgese MG, Schiavone S, Govoni S, Cuomo V, Trabace L (2010) Soluble beta amyloid(1-42): a critical player in producing behavioural and biochemical changes evoking depressive-related state? Br J Pharmacol 159(8):1704 1715

23. Pomara N, Sidtis JJ (2010) Brain neurotoxic amyloid-beta peptides: their potential role in the pathophysiology of depression and as molecular therapeutic targets. Br J Pharmacol 161(4):768-770

24. Sun X, Steffens DC, Au R, Folstein M, Summergrad P, Yee J, Rosenberg I, Mwamburi DM et al (2008) Amyloid-associated depression: a prodromal depression of Alzheimer disease? Arch Gen Psychiatry 65(5):542-550

25. McEwen BS, Eiland L, Hunter RG, Miller MM (2012) Stress and anxiety: structural plasticity and epigenetic regulation as a consequence of stress. Neuropharmacology 62(1):3-12. doi:10.1016/j. neuropharm.2011.07.014

26. Harauma A, Moriguchi T (2011) Dietary n-3 fatty acid deficiency in mice enhances anxiety induced by chronic mild stress. Lipids 46(5):409-416. doi:10.1007/s11745-010-3523-Z

27. Ikemoto A, Ohishi M, Sato Y, Hata N, Misawa Y, Fujii Y, Okuyama H (2001) Reversibility of n-3 fatty acid deficiency-induced alterations of learning behavior in the rat: level of n- 6 fatty acids as another critical factor. J Lipid Res 42(10):1655-1663

28. Fedorova I, Salem N Jr (2006) Omega-3 fatty acids and rodent behavior. Prostaglandins Leukot Essent Fat Acids 75(4-5):271289. doi:10.1016/j.plefa.2006.07.006

29. McNamara RK, Vannest JJ, Valentine CJ (2015) Role of perinatal long-chain omega-3 fatty acids in cortical circuit maturation: mechanisms and implications for psychopathology. World J Psychiatry 5(1):15-34. doi:10.5498/wjp.v5.11.15

30. Aid S, Vancassel S, Poumes-Ballihaut C, Chalon S, Guesnet P, Lavialle M (2003) Effect of a diet-induced n-3 PUFA depletion on cholinergic parameters in the rat hippocampus. J Lipid Res 44(8):1545-1551. doi:10.1194/jlr.M300079-JLR200

31. Monteggia LM, Luikart B, Barrot M, Theobold D, Malkovska I, Nef S, Parada LF, Nestler EJ (2007) Brain-derived neurotrophic factor conditional knockouts show gender differences in depression-related behaviors. Biol Psychiatry 61(2):187-197

32. Choleris E, Thomas AW, Kavaliers M, Prato FS (2001) A detailed ethological analysis of the mouse open field test: effects of diazepam, chlordiazepoxide and an extremely low frequency pulsed magnetic field. Neurosci Biobehav Rev 25(3):235-260

33. Porsolt RD, Bertin A, Jalfre M (1977) Behavioral despair in mice: a primary screening test for antidepressants. Arch Int Pharmacodyn Ther 229(2):327-336

34. Cryan JF, Valentino RJ, Lucki I (2005) Assessing substrates underlying the behavioral effects of antidepressants using the modified rat forced swimming test. Neurosci Biobehav Rev 29(4-5):547569

35. Madore C, Nadjar A, Delpech JC, Sere A, Aubert A, Portal C, Joffre C, Laye S (2014) Nutritional n-3 PUFAs deficiency during perinatal periods alters brain innate immune system and neuronal plasticity-associated genes. Brain Behav Immun 41:22-31. doi:10. 1016/j.bbi.2014.03.021

36. Prut L, Belzung C (2003) The open field as a paradigm to measure the effects of drugs on anxiety-like behaviors: a review. Eur J Pharmacol 463(1-3):3-33

37. Adams PB, Lawson S, Sanigorski A, Sinclair AJ (1996) Arachidonic acid to eicosapentaenoic acid ratio in blood correlates positively with clinical symptoms of depression. Lipids 31(Suppl): S157-161

38. Green P, Hermesh H, Monselise A, Marom S, Presburger G, Weizman A (2006) Red cell membrane omega-3 fatty acids are decreased in nondepressed patients with social anxiety disorder. Eur Neuropsychopharmacol 16(2):107-113. doi:10.1016/j. euroneuro.2005.07.005 
39. Larrieu T, Hilal ML, Fourrier C, De Smedt-Peyrusse V, Sans N, Capuron L, Laye S (2014) Nutritional omega-3 modulates neuronal morphology in the prefrontal cortex along with depression-related behaviour through corticosterone secretion. Transl Psychiatry 4: e437. doi:10.1038/tp.2014.77

40. Boersma GJ, Lee RS, Cordner ZA, Ewald ER, Purcell RH, Moghadam AA, Tamashiro KL (2014) Prenatal stress decreases Bdnf expression and increases methylation of Bdnf exon IV in rats. Epigenetics 9(3):437-447. doi:10.4161/epi.27558

41. Schaaf MJ, de Jong J, de Kloet ER, Vreugdenhil E (1998) Downregulation of BDNF mRNA and protein in the rat hippocampus by corticosterone. Brain Res 813(1):112-120

42. Schaaf MJ, De Kloet ER, Vreugdenhil E (2000) Corticosterone effects on BDNF expression in the hippocampus. Implications for memory formation. Stress 3(3):201-208

43. Sarrazin N, Di Blasi F, Roullot-Lacarriere V, Rouge-Pont F, Le Roux A, Costet P, Revest JM, Piazza PV (2009) Transcriptional effects of glucocorticoid receptors in the dentate gyrus increase anxiety-related behaviors. PLoS One 4(11):e7704. doi:10.1371/ journal.pone.0007704

44. Stetler C, Miller GE (2011) Depression and hypothalamic-pituitaryadrenal activation: a quantitative summary of four decades of research. Psychosom Med 73(2):114-126. doi:10.1097/PSY. 0b013e31820ad12b

45. Carlezon WA Jr, Mague SD, Parow AM, Stoll AL, Cohen BM, Renshaw PF (2005) Antidepressant-like effects of uridine and omega-3 fatty acids are potentiated by combined treatment in rats. Biol Psychiatry 57(4):343-350. doi:10. 1016/j.biopsych.2004.11.038

46. Caraci F, Copani A, Nicoletti F, Drago F (2010) Depression and Alzheimer's disease: neurobiological links and common pharmacological targets. Eur J Pharmacol 626(1):64-71. doi:10.1016/j. ejphar.2009.10.022

47. Sometani A, Kataoka H, Nitta A, Fukumitsu H, Nomoto H, Furukawa S (2001) Transforming growth factor-betal enhances expression of brain-derived neurotrophic factor and its receptor, TrkB, in neurons cultured from rat cerebral cortex. J Neurosci Res 66(3):369-376

48. Myint AM, Leonard BE, Steinbusch HW, Kim YK (2005) Th1, Th2, and Th3 cytokine alterations in major depression. J Affect Disord 88(2):167-173. doi:10.1016/j.jad.2005.07.008

49. Tomasdottir V, Vikingsson A, Freysdottir J, Hardardottir I (2013) Dietary fish oil reduces the acute inflammatory response and enhances resolution of antigen-induced peritonitis. J Nutr Biochem 24(10):1758-1765. doi:10.1016/j.jnutbio.2013.03.005

50. Hida M, Fujita H, Ishikura K, Omori S, Hoshiya M, Awazu M (2003) Eicosapentaenoic acid inhibits PDGF-induced mitogenesis and cyclin D1 expression via TGF-beta in mesangial cells. J Cell Physiol 196(2):293-300. doi:10.1002/jcp.10298

51. Hill MN, McEwen BS (2010) Involvement of the endocannabinoid system in the neurobehavioural effects of stress and glucocorticoids. Prog Neuro-Psychopharmacol Biol Psychiatry 34(5):791797. doi:10.1016/j.pnpbp.2009.11.001

52. Hill MN, McLaughlin RJ, Morrish AC, Viau V, Floresco SB, Hillard CJ, Gorzalka BB (2009) Suppression of amygdalar endocannabinoid signaling by stress contributes to activation of the hypothalamicpituitary-adrenal axis. Neuropsychopharmacology 34(13):27332745. doi:10.1038/npp.2009.114

53. Gobbi G, Bambico FR, Mangieri R, Bortolato M, Campolongo P, Solinas M, Cassano T, Morgese MG et al (2005) Antidepressantlike activity and modulation of brain monoaminergic transmission by blockade of anandamide hydrolysis. Proc Natl Acad Sci U S A 102(51):18620-18625. doi:10.1073/pnas.0509591102

54. Kathuria S, Gaetani S, Fegley D, Valino F, Duranti A, Tontini A, Mor $\mathrm{M}$, Tarzia $\mathrm{G}$ et al (2003) Modulation of anxiety through blockade of anandamide hydrolysis. Nat Med 9(1):76-81. doi:10.1038/nm803
55. McLaughlin RJ, Hill MN, Dang SS, Wainwright SR, Galea LA, Hillard CJ, Gorzalka BB (2013) Upregulation of CB(1) receptor binding in the ventromedial prefrontal cortex promotes proactive stress-coping strategies following chronic stress exposure. Behav Brain Res 237:333-337. doi:10.1016/j.bbr.2012.09.053

56. Detke MJ, Rickels M, Lucki I (1995) Active behaviors in the rat forced swimming test differentially produced by serotonergic and noradrenergic antidepressants. Psychopharmacology 121(1):66-72

57. Patrick RP, Ames BN (2015) Vitamin D and the omega-3 fatty acids control serotonin synthesis and action, part 2: relevance for ADHD, bipolar disorder, schizophrenia, and impulsive behavior. FASEB J 29(6):2207-2222. doi:10.1096/fj.14-268342

58. Calder PC (2001) omega 3 polyunsaturated fatty acids, inflammation and immunity. World Rev Nutr Diet 88:109-116

59. James MJ, Gibson RA, Cleland LG (2000) Dietary polyunsaturated fatty acids and inflammatory mediator production. Am J Clin Nutr 71(1 Suppl):343S-348S

60. Calder PC (2013) n-3 fatty acids, inflammation and immunity: new mechanisms to explain old actions. Proc Nutr Soc 72(3):326-336. doi:10.1017/S0029665113001031

61. Graeber MB, Li W, Rodriguez ML (2011) Role of microglia in CNS inflammation. FEBS Lett 585(23):3798-3805. doi:10.1016/ j.febslet.2011.08.033

62. Blazevic S, Colic L, Culig L, Hranilovic D (2012) Anxiety-like behavior and cognitive flexibility in adult rats perinatally exposed to increased serotonin concentrations. Behav Brain Res 230(1): 175-181. doi:10.1016/j.bbr.2012.02.001

63. Sachs BD, Ni JR, Caron MG (2015) Brain 5-HT deficiency increases stress vulnerability and impairs antidepressant responses following psychosocial stress. Proc Natl Acad Sci U S A 112(8): 2557-2562. doi:10.1073/pnas.1416866112

64. Haenisch B, Bilkei-Gorzo A, Caron MG, Bonisch H (2009) Knockout of the norepinephrine transporter and pharmacologically diverse antidepressants prevent behavioral and brain neurotrophin alterations in two chronic stress models of depression. J Neurochem 111(2):403-416. doi:10.1111/j.1471-4159.2009.06345.x

65. Mathieu G, Denis S, Langelier B, Denis I, Lavialle M, Vancassel S (2010) DHA enhances the noradrenaline release by SH-SY5Y cells. Neurochem Int 56(1):94-100. doi:10.1016/j.neuint.2009.09.006

66. Braun D, Madrigal JL, Feinstein DL (2014) Noradrenergic regulation of glial activation: molecular mechanisms and therapeutic implications. Curr Neuropharmacol 12(4):342-352. doi:10.2174/ 1570159X12666140828220938

67. Counts SE, Mufson EJ (2010) Noradrenaline activation of neurotrophic pathways protects against neuronal amyloid toxicity. J Neurochem 113(3):649-660. doi:10.1111/j.1471-4159.2010. 06622.x

68. Liu X, Ye K, Weinshenker D (2015) Norepinephrine protects against amyloid-beta toxicity via TrkB. J Alzheimers Dis 44(1): 251-260. doi:10.3233/JAD-141062

69. Heneka MT, Nadrigny F, Regen T, Martinez-Hernandez A, Dumitrescu-Ozimek L, Terwel D, Jardanhazi-Kurutz D, Walter J et al (2010) Locus ceruleus controls Alzheimer's disease pathology by modulating microglial functions through norepinephrine. Proc Natl Acad Sci U S A 107(13):6058-6063

70. Hjorth E, Zhu M, Toro VC, Vedin I, Palmblad J, Cederholm T, Freund-Levi Y, Faxen-Irving G et al (2013) Omega-3 fatty acids enhance phagocytosis of Alzheimer's disease-related amyloid-beta42 by human microglia and decrease inflammatory markers. $\mathrm{J}$ Alzheimers Dis 35(4):697-713. doi:10.3233/JAD-130131

71. Sanz JM, Chiozzi P, Idzko M, Falzoni S, Fellin S, Trabace L, Di Virgilio F (2009) Activation of microglia by amyloid $\beta$ requires P2X7 receptor expression. J Immunol 182(7):4378-4385

72. Thomas AJ, Davis S, Morris C, Jackson E, Harrison R, O'Brien JT (2005) Increase in interleukin-1beta in late-life depression. Am J Psychiatry 162(1):175-177. doi:10.1176/appi.ajp.162.1.175 
73. Osorio RS, Gumb T, Pomara N (2014) Soluble amyloid-beta levels and late-life depression. Curr Pharm Des 20(15):2547-2554

74. Goshen I, Kreisel T, Ben-Menachem-Zidon O, Licht T, Weidenfeld J, Ben-Hur T, Yirmiya R (2008) Brain interleukin-1 mediates chronic stress-induced depression in mice via adrenocortical activation and hippocampal neurogenesis suppression. Mol Psychiatry 13(7):717-728. doi:10.1038/sj.mp.4002055

75. Caughey GE, Mantzioris E, Gibson RA, Cleland LG, James MJ (1996) The effect on human tumor necrosis factor alpha and interleukin 1 beta production of diets enriched in n-3 fatty acids from vegetable oil or fish oil. Am J Clin Nutr 63(1):116-122

76. Song C, Li X, Leonard BE, Horrobin DF (2003) Effects of dietary n-3 or n-6 fatty acids on interleukin-1beta-induced anxiety, stress, and inflammatory responses in rats. J Lipid Res 44(10):1984-1991. doi:10.1194/jlr.M300217-JLR200

77. Cho SM, Kim HV, Lee S, Kim HY, Kim W, Kim TS, Kim DJ, Kim Y (2014) Correlations of amyloid-beta concentrations between CSF and plasma in acute Alzheimer mouse model. Sci Rep 4:6777. doi: 10.1038/srep06777

78. Gu Y, Schupf N, Cosentino SA, Luchsinger JA, Scarmeas N (2012) Nutrient intake and plasma beta-amyloid. Neurology 78(23):18321840. doi:10.1212/WNL.0b013e318258f7c2

79. Morgese MG, Tucci P, Colaianna M, Zotti M, Cuomo V, Schiavone S, Trabace L (2014) Modulatory activity of soluble beta amyloid on HPA axis function in rats. Curr Pharm Des 20(15):2539-2546

80. Pomara N, Sidtis J (2007) Possible therapeutic implication of Abeta disturbances in depression. Int J Geriatr Psychiatry 22(9):931-932. doi:10.1002/gps.1763
81. Gudmundsson P, Skoog I, Waern M, Blennow K, Palsson S, Rosengren L, Gustafson D (2007) The relationship between cerebrospinal fluid biomarkers and depression in elderly women. Am J Geriatr Psychiatr 15(10):832-838. doi:10.1097/JGP. Ob013e3180547091

82. Chen M, Inestrosa NC, Ross GS, Fernandez HL (1995) Platelets are the primary source of amyloid beta-peptide in human blood. Biochem Biophys Res Commun 213(1):96-103. doi:10.1006/ bbrc. 1995.2103

83. Tang K, Hynan LS, Baskin F, Rosenberg RN (2006) Platelet amyloid precursor protein processing: a bio-marker for Alzheimer's disease. J Neurol Sci 240(1-2):53-58. doi:10.1016/j.jns.2005.09. 002

84. Giedraitis V, Sundelof J, Irizarry MC, Garevik N, Hyman BT, Wahlund LO, Ingelsson M, Lannfelt L (2007) The normal equilibrium between CSF and plasma amyloid beta levels is disrupted in Alzheimer's disease. Neurosci Lett 427(3):127-131. doi:10.1016/j. neulet.2007.09.023

85. Liem ET, Sauer PJ, Oldehinkel AJ, Stolk RP (2008) Association between depressive symptoms in childhood and adolescence and overweight in later life: review of the recent literature. Arch Pediatr Adolesc Med 162(10):981-988. doi:10.1001/archpedi.162.10.981

86. Pine DS, Goldstein RB, Wolk S, Weissman MM (2001) The association between childhood depression and adulthood body mass index. Pediatrics 107(5):1049-1056

87. Grant WB (2014) Trends in diet and Alzheimer's disease during the nutrition transition in Japan and developing countries. J Alzheimers Dis 38(3):611-620. doi:10.3233/JAD-130719 